\title{
"La literacidad para legislar": Una ideología hegemónica reproducida por el diario peruano Correo*
}

\author{
"Literacy to Legislate": A Hegemonic Ideology Reproduced by \\ the Peruvian Newspaper Correo
}

Marco Antonio Lovón Cueva**

\section{RESUMEN}

Este estudio analiza la relación entre la ortografía de la excongresista Supa y las valoraciones expresadas por el diario Correo en torno a lo que se considera "la escritura" para legislar. Metodológicamente, se realizó un análisis ideológico del discurso periodístico. En el trabajo se identificaron dos representaciones acerca de la ortografía y la escritura en general. Considerando el modelo autónomo de la literacidad, se explica que Correo asume que la escritura crea y desarrolla habilidades cognitivas de nivel superior, y que conduce al progreso económico, por lo que cualquier persona no puede ser parlamentaria. Por otro lado, desde los nuevos estudios de la literacidad, se concluye que estas asunciones resultan ser creencias insostenibles, e incluso generadoras de racismo, porque la literacidad trasciende los aspectos técnicos y raciales.

\begin{abstract}
This study analyzes the relationship between the spelling of former congresswoman Supa and the related assessments by the Correo newspaper of what is considered "writing" for legislation. The methodology applied is an ideological analysis of journalistic discourse. The paper identifies two representations of spelling and writing in general. Considering the autonomous
\end{abstract}

Palabras clave: literacidad, parlamento, política, ortografía, mujer.

Keywords: literacy, Congress, politics, spelling, woman

Este trabajo fue desarrollado en la Maestría y concluido en el marco de apoyo al incentivo de los proyectos de investigación de la Universidad Peruana de Ciencias Aplicadas (UPC), Área de Humanidades.

** Peruano. Magíster de la Pontificia Universidad Católica del Perú, Lima, Perú. mlovon@upc.edu.pe 
model of literacy, it is explained that the newspaper assumes that writing creates and develops higher-level cognitive skills, and that it leads to economic progress, so that not everyone can be a member of Congress. On the other hand, from the new studies of literacy, it is concluded that these assumptions turn out to be unsustainable beliefs and even generate racism, because literacy goes beyond technical and racial aspects. 


\section{Introducción}

El 17 de abril del 2009, el diario Correo hizo noticia con el siguiente titular “¿Qué nivel! Urge Coquito para congresista Supa”, el cual evidenciaba el reproche, la censura y el desdén del diario hacia la escritura personal o privada de la excongresista cusqueña. El libro Coquito se empleaba en los primeros años de las escuelas primarias peruanas para el aprendizaje de la ortografía.

Según Cervera (2016), los titulares de opinión se construyen discursivamente para orientar y persuadir al lector. Hilaria Supa es bilingüe quechua-castellano, lenguas que aprendió por ella misma, puesto que no recibió educación formal por la ausencia de escuelas en su zona de origen, lo cual no reconoció el diario:

"Me indigna y rechazo profundamente que se hayan atrevido a invadir mi privacidad (...) nunca he entrado a la escuela porque nunca he tenido oportunidad", dijo la legisladora aludida, una exdirigente campesina defensora de las mujeres que representa a la región de Cusco (El Universo, 2009, párr. 7).

El diario Correo (2009a) se lamentaba por las formas de escribir de Hilaria Supa, quien anotó entre sus apuntes: "comgreso De la rePoBleca si Discotio lasituasion de Brai ovo Muchas ParticiPasion", sin considerar, desde un punto de vista lingüístico, la influencia que ejercía la lengua materna en su escritura, representada en los cambios vocálicos; o desde un punto de vista social, no contemplaba la carencia de escolaridad para explicar la práctica escribal de Supa, quien a pesar de ello llegó a ser parlamentaria del Congreso durante el periodo 20062011 en el que gobernaba el expresidente Alan García. La congresista, como otras tantas personas, provenía de la zona rural de la Sierra del Perú y vivió en una comunidad que no estuvo privilegiada con la enseñanza y uso de la escritura. Actualmente en el Perú aún hay zonas en las que no existen escuelas o en las que lenguas como el quechua o el aimara se encuentran en estado de segundas lenguas, por lo que se requiere de la enseñanza de las lenguas originarias con metodologías de segundas lenguas (Lovón, 2016). Entonces, en su titular el diario Correo solo se limitaba a cuestionar, señalar y horrorizar a los lectores con los escritos de Supa, y atribuir, en última instancia, un aleccionamiento acerca de cómo debería escribir una congresista. Para Correo, era un 
escándalo tener a una parlamentaria aparentemente con escasas habilidades cognitivas y sostenía: "es indiscutible que una persona con una instrucción tan (...) elemental (...) poco puede aportar a la elaboración de leyes". El mensaje del diario era claro: debía letrarse a la excongresista. En otras palabras, ella debía ser letrada, como se han letrado las comunidades rurales (Zavala, 2001).

Las inestabilidades vocálicas que presentaba la escritura de la congresista es un fenómeno muy común en el castellano andino, variedad lingüística válida del castellano, y que suele percibirse en los discursos de sus hablantes, el cual no debería dar paso a ningún tipo de discriminación ni desprecio, pues de acuerdo con la posición científica de la lingüística, sustentada por Liliana Sánchez: "No existe ningún rasgo de pronunciación, de vocabulario o de gramática que se pueda considerar más correcto que otro, porque en principio los sonidos son solo eso: sonidos" (Pérez, 2004). Lo que el diario Correo mostraba y legitimaba, por tanto, eran actitudes sociales en cuanto a la escritura, el lenguaje, las lenguas y los hablantes, que suelen ser la expresión de preferencias producidas por la sociedad limeña acerca del estatus y prestigio de la norma estándar y del estatus y prestigio que han adquirido sus hablantes económica, social y políticamente en el país.

Al mismo tiempo, el diario Correo ponía en entredicho la capacidad de legislar de la congresista, a raíz del manejo de la técnica de escribir "correctamente", aun cuando sus escritos representaban muy bien lo que ella deseaba apuntar y recordar. El periodista Aldo Mariátegui, representante del diario, la consideró "inepta" e "inútil": "Una persona así posiblemente solo se va limitar a (...) oponerse, a estar a la defensiva ante cualquier idea nueva, a ser prejuiciosa" (Correo, 2009b). Con esta declaración, la valoración negativa de Correo no se limitaba a las formas de escribir de Supa, sino que se extendía a su capacidad de legislar como congresista. La escritura se asociaba con la actividad y la capacitación política (organización, manejo, democracia, etc.), de manera específica y con formas de movilizarse y desenvolverse en el ejercicio de su cargo parlamentario. Esto se convirtió - y creemos que aún permanece- en un eje de debate en la agenda nacional e incluso global.

En efecto, algunos ciudadanos creen todavía que para ser congresista el representante debe escribir bien. Estas formas de pensar se han 
naturalizado y suelen ser verbalizadas. Por ejemplo, en un foro peruano, el participante identificado como Leodent (2009) indicó - paradójicamente, con sus propias faltas de ortografía-, lo siguiente: "Todo aquel que aspire a ser congresista de la republica, debe de reunir no solo condiciones basicas sino especiales. No es problema de discriminacion, es cuestion de orden y sentido común (sic)" (párr. 1). Los peligros de pensar al otro como inferior por su escritura sitúan al Perú en tiempos decimonónicos - racistas, excluyentes, señoriales, paternalistas-, que por sí solos alejan al país de la "modernidad" que Aldo Mariátegui intenta defender. Excluir a los seres humanos por su ortografía es excluir a masas de personas en el Perú o en el mundo (Sebba, 2009). Un país moderno es un país inclusivo y de oportunidades en condiciones de igualdad y respeto (Araníbar, 2012).

El presente estudio abordó la relación establecida entre la ortografía de la congresista Supa y las creencias del diario Correo acerca de la escritura. En este sentido, analizamos las formas de pensar que se asumían en la prensa estándar limeña. Específicamente, se analizó la falacia argumentativa del diario que sostenía que una parlamentaria era incapaz de cumplir su rol político por sus errores ortográficos en español como segunda lengua. Para ello, recurrimos principalmente al análisis crítico del discurso (ACD), enfoque a partir del cual se examinaron las representaciones sociales construidas en función de las estrategias léxico-discursivas empleadas e insertamos el análisis en las concepciones referidas a la literacidad.

En las siguientes secciones detallamos los principales enfoques teóricos, y la metodología y el análisis de la información discursiva. En la sección final, discutimos los resultados y resaltamos la implicancia de las valoraciones referidas a la escritura en la sociedad peruana.

\section{Los estudios en torno a la literacidad}

Para entender las asunciones del diario Correo sobre la escritura es necesario entender los modelos que estudian la literacidad. De esta forma, por un lado, se encuentran las teorías de la gran división (en adelante TGD), que defienden básicamente la existencia de una "mente letrada", diferente de una "mente oral" y, por otro, se encuentran los nuevos estudios de literacidad (en adelante NEL), que sostienen que la escritura es un producto cultural que se arraiga en 
prácticas sociales donde no tiene sentido la dicotomía "letrado" frente "iletrado", subrayando la importancia del entorno y la dimensión comunitaria.

\subsection{Las teorías de la gran división}

Las TGD hacen una distinción tajante entre oralidad y escritura y asumen que existe una mente oral y una mente letrada diferentes y desiguales (Street, 1993). En otras palabras, hay una división entre culturas orales y culturas escribales, o entre pensamiento oral y pensamiento escrito. Para estas teorías, una vez dominada la escritura, esta permitiría adquirir competencias de pensamiento elevadas.

Las TGD se centran en el estudio de la escritura y la alfabetización, según las cuales un letrado desarrolla su pensamiento en un nivel más alto (estructurado, coherente, sin redundancias) que un iletrado. Estas teorías se concentran en analizar la escritura vinculada con los procesos cognitivos, es decir, de forma totalmente aislada de otros factores, donde el hecho de escribir se entiende como una cuestión cognitiva. Para estas teorías, por tanto, la escritura está descontextualizada de lo social, en otras palabras, es una herramienta neutral o independiente de lo social.

Desde esta óptica, las TGD también se conocen como "visión autónoma de la escritura" o "modelo autónomo". A esta perspectiva le interesan los principios lógicos del pensamiento y concibe que la alfabetización conduce al progreso, la movilidad social y la civilización (Braslavsky, 2003). Así, alfabetizar implica decodificar y manejar signos escritos a través de la lectura y escritura, esto es, una habilidad técnica. Cognitivamente, lo interesante aquí es que la escritura y la alfabetización traen ventajas en el individuo: le permite procesar la información, registrarla, comunicarla e incluso permanecer en el tiempo. Específicamente, el modelo autónomo:

- Enfatiza los aspectos técnicos de la escritura, independientemente de los objetivos y contextos específicos.

- Atribuye que la escritura implica necesariamente una serie de cambios cognitivos.

- Considera que la escritura conduce al desarrollo de habilidades cognitivas superiores. 
- Manifiesta que la escritura distancia a la persona o autores de lo escrito.

- Establece que la escritura marca diferencias entre individuos y culturas que logran el progreso social de los que no lo hacen.

Para el modelo autónomo, la escritura es la clave para la transformación de la conciencia:

Sin la escritura, el pensamiento escolarizado no pensaría ni podría pensar como lo hace, no solo cuando está ocupado en escribir, sino incluso normalmente cuando articula sus pensamientos de manera oral. Más que cualquier otra invención particular, la escritura ha transformado la conciencia humana (Ong, 1997, p. 8).

Desde esta lógica, la escritura es la herramienta que moldea o modifica el pensamiento, por lo que la organización del pensamiento depende, por ende, de la escritura, ya que ella estructura o configura las formas de decir las cosas. Para Olson (1998), la escritura produce cambios psicológicos, formas de representación y de conciencia donde la escritura se convierte en un fin en sí mismo. Para este paradigma, escribir es suficiente para abordar y dominar un conjunto de procesos lingüísticos y psicológicos que la implican. Para Ong (1997), en tanto, el pensamiento y la expresión de las culturas orales presentaban una mentalidad distinta de las culturas caligráficas, que sí poseían escritura. Así afirma: "En una cultura oral, la restricción de las palabras al sonido determina no solo los modos de expresión, sino también los procesos de pensamiento" (p. 40). Para el autor, las culturas ágrafas, por ejemplo, redundan, por lo que desde una postura determinista y reduccionista, conjetura y establece que el pensamiento de las culturas orales se caracteriza por ser formulaico, fijo y mnemotécnico, distinto del pensamiento letrado que es lógico, racional y abstracto. De este modo, la escritura reestructura la conciencia y forma seres humanos distintos de los hablantes de culturas orales: "el examen abstractamente explicativo, ordenador y consecutivo de fenómenos o verdades reconocidas resulta imposible sin la escritura y la lectura" (Ong, 1997, p. 4) señala el autor. Por ello, propone un paralelo y una disyuntiva con la oralidad, al formular que existen dos tipos de pensamiento: el oral y el escrito. En su defensa por la escritura, sugiere una serie de características que la definen o caracterizan, indicando que el discurso escrito: 
- está libre de contextos,

- es inherentemente irrefutable,

- está masificado debido a la imprenta,

- le da vida a la crítica,

- aunque la escritura es una herramienta artificial, es asumida como natural por los seres humanos,

- ha moldeado e impulsado la actividad intelectual,

- es un método de registro de datos, fechas, gastos,

- es fácil de aprender si se cuenta con un alfabeto como el griego (con vocales y reducido a un número de símbolos de asequible lectura),

- tiene mayor fuerza que las palabras habladas, pues su grado de credibilidad es mayor,

- permite al escritor alejarse de todos - una operación eminentemente solipsista-,

- genera distancia, precisión y magnos vocabularios,

- crea códigos distintos de los códigos orales,

- ha creado la retórica académica; y

- ha puesto en marcha la ciencia moderna, entre otras particularidades.

De este modo, para Ong (1997) y desde una postura evolucionista, la escritura produjo un cambio trascendental en la expresión y en el pensamiento, relacionándola con formas de pensamiento, habilidades cognitivas, facilidad en la lógica, abstracción y operaciones mentales (Ames, 2002).

Estos planteamientos provocaron que se desestimaran las culturas orales y se generara una segregación sociocultural hacia ellas, ya que para esta perspectiva todos los grupos humanos pasarían por los mismos procesos cognitivos y llegarían a las mismas metas una vez involucrados con la escritura. Por el contrario, los sujetos que no incorporaran la escritura eran vistos como sujetos deficitarios, ya que para las TGD la escritura por sí sola hacía lo mismo en todos los individuos, lugares y tiempos. De acuerdo con Street (1995), los iletrados carecen de todas estas cualidades, tendiendo a pensar en términos menos abstractos, a estar embebidos en su contexto, así como también a ser menos críticos y capaces de reflexionar acerca de la naturaleza del lenguaje que utilizan. 
Finalmente, para este modelo la escritura habría transformado la mente y la sociedad. Como señala Ames (2002) "En el ámbito social, la escritura es vista por lo tanto como necesaria para el progreso social, la modernización, la industrialización y la participación en el orden económico mundial" (p. 73). Esto implica que la escritura es concebida como un fin mesiánico, moderno, y productivo, y, por ello, habría que someterse a ella. La escritura y sus fines dependían de la escritura misma y no de los individuos, quienes en la práctica le otorgan sentido y usos en contextos específicos. Se trata de un modelo que postula un desarrollo lineal de la oralidad a la escritura y que, a pesar de las ventajas individuales que podría traer, correspondería a un enfoque determinista.

\subsection{Los nuevos estudios de la literacidad}

Los NEL, por su parte, reconocen la importancia del contexto social. La escritura se usa en determinados contextos, con fines específicos, sobre todo en una sociedad con relaciones de poder establecidas. La literacidad implica hacer uso de la palabra escrita para expresarse, comunicarse, obtener y producir información (Ames, 2002). Desde esta perspectiva, la escritura es un producto cultural no neutral que se arraiga en prácticas sociales contextualizadas (Barton y Hamilton, 2004), en el cual se desdibuja la dicotomía letrado frente iletrado. Lo que aparece en este caso son diversas formas de emplear y expresar la lengua escrita, es decir, existen diversos usos sociales de la escritura, los cuales la modifican, o bien, sufre cambios cuando las personas se apropian de ella, sobre todo activamente (Rockwell, 2000). No se trata, entonces, de un enfoque en el que la escritura es mecánica o determinista, sino más bien existen formas hegemónicas de la escritura, las cuales invisibilizan otros usos sociales o literacidades vernaculares que ameritan visibilizarse. Desde esta perspectiva, la escritura no es una competencia individual ni está centrada exclusivamente en lo que se hace en la escuela, sino que cobra sentido en un entorno sociocultural o en comunidad dada.

De este modo, sobre la base de trabajos de campo o etnográficos, los NEL recusan los postulados del modelo autónomo. Así, desde una perspectiva etnográfica, no existiría evidencia empírica de una definición universal o estándar de la literacidad referente a una predispo- 
sición a producir pensamiento independiente (Ames, 2002). La escritura como práctica social sitúa los textos sociohistóricamente, lo cual implica que las personas escriben en contextos particulares para desarrollar funciones concretas afectadas por relaciones de poder. Para este modelo, entonces, la práctica de enseñar a escribir no es neutral, sino que en todos los casos es producto de las estructuras de poder de una sociedad y de las instituciones en las que se adquiere, tales como la escuela, la familia o la iglesia (Braslavsky, 2003). Por eso, este modelo es también conocido como "modelo ideológico". A partir de estos postulados se pueden explicar las relaciones de poder económicas y sociales que se usan para representar los arquetipos de los alfabetos y analfabetos, así como también reconocer la existencia de ideologías en torno a la escritura y sus ventajas, las cuales son creadas desde posiciones sociales privilegiadas, que penetran en los profesores, en los alumnos y en el aprendizaje, y llegan hasta la prensa.

Dentro de los NEL las literacidades difieren unas de otras debido a las formas en que se practican y convencionalizan socialmente. Las maneras de acercarse al texto, y también a la lectura dependen de las socializaciones y de las tradiciones que legitiman su uso, así como también de las necesidades y del distanciamiento de los mismos individuos, de los patrones discursivos que se organizan en torno a ellas $\mathrm{y}$, sobre todo, de contextos específicos y marcos culturales, donde los aspectos lingüísticos como la influencia de la lengua materna tiene importancia y justificación. La escritura no es un fin en sí misma, sino que está en relación con lo que hacen las personas. Para este modelo, las literacidades impuestas como las autogeneradas pueden converger: un individuo puede escribir de una manera menos formal en sus anotaciones personales, pero de manera más formal al dirigirse al público, y de esta manera podemos explicar que no todo el tiempo uno escribe formalmente.

Scribner y Cole (2001) han intentado demostrar la importancia de los NEL y contradecir los postulados de las TGD. Según ellos, sobre la base de las literacidades de los vai, un grupo de indígenas liberianos quienes manejan tres alfabetos (el arábigo, para la lectura y la memorización del Corán; el romano, para la lectura y escritura de temas gubernamentales; y el silabario vai, para la escritura de registros y cartas), demuestran que las destrezas cognitivas supuestamente superiores 
que se obtienen con la escritura no aumentan el uso de destrezas cognitivas generales y, en consecuencia, no atestiguan una diferenciación con "la mentalidad oral" asumida por Ong y los partidarios del modelo autónomo. Más bien, establecen que la literacidad se restringe a ciertos contextos y determinadas habilidades relacionadas con la tradición cultural o la promoción que hacen los individuos para cada práctica social (así, los vai pueden resolver tareas de integración auditiva, porque poseen esta destreza gracias a la forma en que procesan su habla, influenciados por las prácticas obtenidas con su silabario, una escritura silábica que no demarca divisiones entre las palabras). Por consiguiente, la categorización y el razonamiento abstracto deberían entenderse en relación con contextos específicos y tradiciones y prácticas específicas (una destreza particular se fortalece por el desarrollo de una determinada literacidad); sobre todo, si de acuerdo con Scribner y Cole (2004), los iletrados vai poseen determinadas habilidades cognitivas que los letrados vai tienen. En esta misma línea, los autores añaden que la literacidad vai se da a expensas del tipo de enseñanza occidental que suele aparecer hegemónicamente en el contexto escolar. Por ende, para ellos, la literacidad es contextual y no universal y ni la escritura ni la educación formal afectan el funcionamiento mental de los individuos. En palabras de Scribner y Cole (2004): "no existe evidencia de que la escritura promueva 'habilidades mentales generales"' (p. 75), por lo que los vai constituyen una evidencia que contradice las posturas estrictamente cognitivas.

Resulta, pues, interesante que Scribner y Cole entiendan la literacidad más allá de cuestiones deterministas, evolucionistas o técnicas, y la sitúen e incorporen dentro de la práctica social y cultural específicas (Ames, 2002). De igual modo, es relevante que dichos autores reconozcan que las afirmaciones acerca de la escritura e incluso sobre la oralidad no deban generalizarse, ya que las funciones, fines, medios, consecuencias y efectos que podría o no producir la escritura o las escrituras no son iguales para todos los contextos, épocas, individuos y deseos.

En suma, los NEL desdeñan la idea de que la escritura se perciba como completamente neutral, ya que esta se relaciona con el poder, las prácticas y los objetivos, entre otros factores. Sin embargo, es justo señalar que esto no implica que las habilidades técnicas y los aspec- 
tos cognitivos tengan su lugar en la literacidad, ya que se entiende que están incorporados dentro de los sistemas culturales y estructuras de poder (Ames, 2002). En este sentido, la escritura no tiene las mismas consecuencias para todos los individuos, en diferentes épocas y espacios (Jiménez y Lovón, 2015).

\section{El castellano andino}

Ahora bien, para entender la ortografía de la congresista Supa es necesario reconocer la variedad lingüística que usó en su escrito personal: se trata del castellano andino.

Esta variedad del castellano se habla en la región andina de Perú, así como en otros países vecinos (en zonas de Ecuador, Bolivia, etc.), y surgió en la época de la Conquista con la castellanización de quechuas y aimara hablantes, cuyo aprendizaje del castellano por parte de las poblaciones indígenas fue un proceso lento e informal (Zavala, 1999), y aún lo es. Este castellano presenta rasgos como el uso de "dice" y "diciendo" a finales de las oraciones, eliminación de objetos directos o quizás doble redundancia de estos, neutralización vocálica o "motoseo", entre otros rasgos. Este último, la neutralización vocálica, se entiende como la falsa percepción que tienen los castellano-hablantes no andinos acerca de la producción vocálica de los castellano-hablantes andinos respecto del uso o la pronunciación de las vocales /e/, /i/, /o/ y /u/, a los que se les atribuye que están invirtiendo las vocales o que estuvieran atinando ciertas veces al uso correcto de las vocales y otras veces no:

Así, pues, el origen del prejuicio radicaría, de un lado, en la percepción 'defectuosa' del hablante del castellano no andino, que no alcanzaría a identificar cabalmente el timbre de la vocal [I] y la categoriza como /i/ o como /e/, con la sensación equivocada de que el hablante del castellano andino estaría invirtiendo las vocales (Pérez, Acurio y Bendezú, 2008, p. 12).

En el Perú esta inversión —o más bien estereotipo lingüístico-, es llamada motoseo, y ha sido usada para crear prejuicios referentes a los hablantes de lenguas originarias quechua y aimara que aprenden castellano (Lovón, 2019b). Según Pérez y Zavala (2010)

Este estereotipo es consistente con un prejuicio extendido en el Perú con relación a las personas de origen andino, a saber, que son 
ignorantes, faltos de inteligencia, incultos, etc. La supuesta incapacidad de 'hablar bien el castellano' refuerza en las personas discriminadoras esta preconcepción (párr. 1).

Esta falsa creencia, asimismo, es utilizada por los castellano-hablantes residentes en Lima quienes asumen que hablan correctamente el castellano (poseen una visión normativa de la lengua), como si sus formas de habla fueran las correctas y las otras no (por ello, creen que las personas de castellano andino estarían deformando el castellano). Siguiendo a Cerrón-Palomino (2003), los castellano-hablantes de Lima reciben una aceptación social mejor en el país, que los castellanohablantes andinos, cuyas formas de hablar son apreciadas de forma despectiva. En Lima, son los grupos de poder los que consideran qué es o no prestigioso, sobre la base de determinados lineamientos del habla culta, respaldados generalmente por instituciones académicas de la lengua estándar, como la Real Academia Española. Por ende, se legitima una variedad lingüística que se concibe como correcta, elegante y autorizada; mientras que la otra se piensa como corrupta, errática y bárbara, por lo que sus hablantes son desprestigiados: a ellos se les suele vincular con conceptos como analfabetos, carentes de ciertas habilidades cognitivas, seres humanos incivilizados o de segunda categoría (Lovón, 2019a).

Todos los prejuicios aquí descritos se originan por las apreciaciones acerca de la oralidad, pero también se extrapolan y se presentan en las valoraciones respecto de la apropiación de la escritura del castellano como segunda lengua (Garatea, 2010). El hablante quechua que aprende a escribir en castellano puede transferir el sistema vocálico de su lengua materna como una forma de procesar la escritura, pero este proceso puede no ser bien visto por los hablantes monolingües de castellano dentro y fuera de la escuela, y dentro y fuera de espacios públicos, por lo que el hablante cuestionado será valorado de manera negativa y asociado a rasgos de precario, incorrecto e incapaz (Zavala, 2002, Zavala y Córdova, 2010). Esto no sucede cuando se trata de un hablante de lengua extranjera que aprende castellano como segunda lengua. En efecto, en el Perú se valora más a los hablantes de inglés, alemán y portugués, por ejemplo, que aun cuando su pronunciación presenta influencias de sus lenguas maternas, son vistos como "graciosos", "nuevos aprendientes", "dedicados al aprendizaje", "ricos", en contraste con 
los hablantes indígenas (RPP, 2013, La República, 2005). Para Muñoz (2015, párr. 8), se es "más tolerable si de una persona extranjera se tratara". Algunos peruanos, por ejemplo, sobre el expresidente Alejandro Toledo, de procedencia indígena, estaban "horrorizados ante el peligro que representaría para el Perú un gobierno de alguien que habla mal el castellano" (La República, 2001). Pareciera que aparentemente aún no se ha perdonado que existan hablantes procedentes de las regiones andinas (Calderón, 2009).

\section{Metodología}

Para analizar el discurso del diario Correo acerca de lo que se considera que debe ser la escritura, hemos seleccionado la portada, la columna editorial del 23 de abril del 2009, la columna editorial del 24 de abril del 2009 - en la que pide perdón, pero no realiza alguna rectificación-, así como otros escritos importantes anteriores. Como se trata de más de un escrito, nos referiremos al Correo, más que a su representante -Aldo Mariátegui-, pues se trata de toda una línea editorial en la que incluso nadie se ha opuesto a los planteamientos procedentes desde la dirección del diario; se trata, entonces, de una visión compartida de este medio de prensa.

Para el análisis, segmentamos el discurso en enunciados, puesto que estos constituyen la unidad principal de la presente investigación. En los enunciados se analizan las palabras y figuras retóricas usadas por el diario. Postulamos que este discurso responde a un racismo encubierto que se guía bajo las asunciones del modelo autónomo respecto de las habilidades cognitivas y el progreso, las que se pueden representar con las siguientes aseveraciones:

- Representación 1: Un legislador que escribe con las normas del castellano estándar posee habilidades cognitivas superiores; uno que escribe en castellano andino posee habilidades cognitivas inferiores.

- Representación 2: Un legislador que escribe con las normas del castellano estándar garantiza el progreso económico; uno que escribe en castellano andino conduce al retroceso.

Ambas posturas, finalmente, justifican formas de pensar como esta representación: Si hablas o escribes mal, no eres capaz de representar ni gobernar el país. 
Por ejemplo, en el Perú se han condenado al candidato presidencial César Acuña y al expresidente Alejandro Toledo por las formas en las que hablan el castellano, las que son percibidas como el habla de castellano andino. Sin embargo no sucedió lo mismo con los expresidentes Alberto Fujimori y Pedro Pablo Kuczynski, cuyas formas de habla han sido percibidas como influidas por lenguas extranjeras prestigiosas o con "acento extranjero" y "respetable", como el japonés o el inglés (Hildebrandt, 2013). Estas representaciones se pueden revelar desde el ACD (Fairclough, 1995) donde el discurso se estudia como texto (material lingüístico) y como una práctica social (formas recurrentes y comunes de realizar una actividad).

Ahora bien, para rechazar la falta de dominio escribal de la congresista Supa y justificar la carencia de educación y capacidad para legislar, el diario Correo recurre a ciertas estrategias léxico-retóricas que se analizarán en el siguiente apartado, pero que adelantamos aquí: adjetivos y verbos, negaciones, implicaciones, analogías y metáforas que se usan para infravalorar a las personas, generar distanciamientos, victimizar al otro para victimizarse y negarse como racista (Wodak y Meyer, 2003). De igual modo, puesto que a Aldo Mariátegui se le ha acusado de repudiador y racista, creemos que una manera académica de evidenciar sus posturas es por medio del ACD, ya que este marco visibiliza las estrategias y representaciones sociales.

Con este propósito, fue útil para esta investigación recurrir a las premisas de los enfoques de la literacidad (EL), porque el tema investigado estaba relacionado con la escritura, los procesos cognitivos y los aspectos sociales. Complementariamente - y cuando fue necesario- articulamos dichos enfoques para describir algunas particularidades.

Por último, a partir del ACD, debemos hacer notar que Mariátegui reproduce un discurso que es compartido por otros ciudadanos, por lo que en última instancia no se trata de un análisis de él como persona, sino de esa pluralidad de voces que sostienen un discurso discriminador.

El corpus se adjunta al final del artículo, en un anexo, donde colocamos numeraciones para identificar informaciones discursivas y analizarlas según los parámetros del ACD. 


\section{Análisis del caso: las representaciones que alimentan el discurso acerca de la literacidad autónoma}

\subsection{Representación 1: Un legislador que escribe con las normas del castellano estándar posee habilidades cognitivas superio- res; uno que escribe en castellano andino posee habilidades cognitivas inferiores}

La manera en que es percibida la escritura de la congresista Supa por parte de Correo se basa en una ideología mayor donde la escritura crea y desarrolla habilidades de nivel superior; lo cual fue expresado a través de su titular “QQué nivel!” (línea 30). Esta creencia generó y genera una representación negativa de la imagen de la congresista como una persona "ignorante", "torpe", "sin educación" (líneas 22, $51,52,143,144)$.

Posteriormente, el periódico indicó que ella no estaba inspirada "por las luces de la cultura" (línea 105). De esta forma, el titular se convierte en contenido analizable que evidencia valoraciones en torno a lo que se considera la escritura y cuáles son sus efectos en los individuos. Así, con el título “¡Qué nivel!” se exageraba la apreciación de la escritura de la congresista, juzgándola de impropia.

De igual modo, el tamaño de la letra y los signos de exclamación en el título resaltaban no solo el asombro, sino sobre todo la desaprobación. Con este título, el diario marcó su distancia y diferencia lingüística y social, porque las anotaciones de la congresista no estaban a la altura y propiedad de lo que se consideró la escritura, o bien, "la correcta escritura". Para Correo, la escritura es aquella que sigue las normas establecidas y otorga capacidades cognitivas superiores y niveles de "alta" cultura. De allí que escribir bien significa escribir sin errores ortográficos - e incluso, sintácticos, como el periódico menciona, aunque no se centrara en este tipo de faltas-, es decir, seguir las convenciones de la escritura actual de la gramática normativa castellana. Se aprecia con ello que la buena escritura se reduce al plano de la ortografía. Sin embargo, la redacción de la congresista le permitía recopilar ideas, registrar pensamientos y rememorar hechos escuchados en el Parlamento, en tanto que sus escritos presentaban cohesión y coherencia semánticas, además de una organización o estructura textual, 
de modo que el problema para Correo eran solamente las transcripciones ortográficas, hiperbolizando el hecho desde lo que este medio consideró que era la escritura.

Para el diario, entonces, - al igual que para muchas personas en la sociedad-, una persona que escribe en castellano andino carece de habilidades cognitivas, lo cual se agrava al tratarse de una autoridad política. De este modo, para exponer a la congresista, Correo mostraba sus escritos como faltas ortográficas fatales (línea 31), las que fueron fotografiadas y por medio de las cuales se cuestionaba su inteligencia (línea 39), pese a que Supa ha sido una activa dirigente y que ha denunciado, por ejemplo, el caso de las esterilizaciones forzadas cometidas en el gobierno de Fujimori, aunque este aspecto no parece ser un indicador de inteligencia para el periódico.

El titular, asimismo, contenía un subtitular en el que se recriminaba la "ineficiencia" y "analfabetismo" de la congresista, enfatizándose lo negativo con el verbo "urge" (línea 28) y la alusión del "Coquito" (línea 29), registrado en cursivas, los cuales conllevan toda una serie de implicaciones y connotaciones: en el caso de "urge" el verbo no solo implica rapidez, sino que se considera apremiante en grado sumo, lo cual deja en entredicho la imparcialidad del periódico Correo, ya que con este verbo no solo se está informando, sino más bien se sugiere e implica la necesidad de cambio.

Más adelante en el texto se hace una analogía con la novela de Gabriel García Márquez El coronel no tiene quien le escriba, cuando el periódico afirma "La congresista no tiene quien le escriba" (línea 32), dando a entender que ella necesitaba de alguien para desplegarse como persona. Sus formas de escribir, mejor dicho, su ortografía, fueron explícitamente desaprobadas (línea 40), incluso sarcásticamente (líneas 35, 36, 41, 92, $125,126)$, censura que estaba acentuada al citarse el libro Coquito (línea 28), con lo cual se desvaloraba y desacreditaba a la congresista al representarla como un infante que debe de aprender a escribir "bien". Con ello se aprecia que para Correo, ser congresista entrañaba el requisito de escribir de forma correcta para desenvolverse como una persona capacitada y ejemplar que merecerá respeto (líneas 49, 85, 146).

En su momento Correo no reconoció que la ortografía de la congresista respondía a la influencia de su lengua materna, a la escolarización 
tardía y a la falta de apropiación de las convenciones ortográficas legitimadas por la normativa española, así como tampoco dio cuenta de los motivos sociales, culturales, ideológicos o de poder que han desfavorecido académicamente a personas como Supa y a muchos ciudadanos. Al respecto, Supa ha dicho en quechua: "Runasimi rimaqmi kani, manan p'enqakunichu" ("soy quechua y no me avergüenzo") (Prensa Libre, 2009) y, además, se sabe que ella accedió a la escuela a los 20 años y su proceso de escolarización no fue el más formal, en comparación con los escolares de las escuelas limeñas, por lo que apropiarse de la escritura debiera reconocerse como un mérito y no como una razón para ser discriminada.

Pese a ello, Correo concibe la literacidad como un factor independiente del contexto social de la apropiación escribal y consideró que las consecuencias individuales, e incluso sociales de los individuos derivarían del carácter intrínseco de esta tecnología (líneas 121, 181, 182), a sabiendas que el rol político y social de la congresista no devino por el dominio de la escritura castellana, sino por su lucha por un país democrático y justo. En este sentido, el diario no vio que Supa escribía lo deseaba obtener y producir, y conocía dos lenguas -el quechua (L1) y el castellano (L2)—, esto es, no la representó como un sujeto cuyas capacidades cognitivas no eran mínimas o insignificantes, o que su actuar demostraba un alto potencial de desenvolvimiento en el mundo - sobre todo en un país multilingüe y multicultural-, sino que por el contrario, hizo hincapié en sus usos del lenguaje para ubicarla en un orden social jerárquico inferior (líneas 122, 123, 124) e infantil (línea 127). Fishman (2004) señala que "En relación con la literacidad, (...) la gente lee y escribe de maneras que son útiles y que tienen sentido para ellos, sin importar cómo su lectura o su escritura puedan parecer a los extraños" (p. 275).

Esta actitud despectiva hacia Supa no es nueva, ya que también quedó en evidencia cuando fue elegida presidenta de la Comisión de Educación, Ciencia, Tecnología, Cultura, Patrimonio Cultural, Juventud y Deporte, del Congreso de la República. En efecto, los excongresistas Carlos Raffo y Mercedes Cabanillas indicaban que ella no tenía la especialidad o especialización en el tema educativo, incluso Raffo señaló que tenía carácter beligerante. Sin embargo, en opinión de la lingüista Vigil (2010) también forma parte del tema educativo el que 
ella conociera "muchísimo sobre las formas de enseñar y aprender de los pueblos quechua-hablantes", ya que eso es "de lo que muchos y muchas especialistas blancas y mestizas no saben nada". Para esta especialista, entonces, el tema educativo no solo estaría circunscrito a la población blanca y mestiza peruana, por lo que las opiniones de los excongresistas estarían privilegiando un tipo de educación, un tipo de castellano y un tipo de peruano, tal como parece implicarlo Correo (línea 128).

\subsection{Representación 2: Un legislador que escribe con las nor- mas del castellano estándar garantiza el progreso económico; uno que escribe en castellano andino conduce al retroceso}

La desaprobación de la escritura de Supa no solo se dirigió a descalificar sus formas de escribir y establecer las supuestas carencias de destrezas cognitivas que colocan finalmente al iletrado por debajo del letrado (líneas 21, 22, 26, 27), sino que también estuvo dirigida a reprochar su actividad legislativa (líneas 104, 137, 229). Ello, porque se piensa que una persona que escribe en castellano andino atrasa el progreso, sobre todo si es autoridad política, como se muestra en la columna del periodista Aldo Mariátegui (líneas 8, 9). Esta percepción se ve incrementada si esa persona defiende las lenguas originarias - lo que en el Perú se asocia también con ideas de "retraso" (líneas 82, 83, 84)-, lo cual llevaría a cuestionar el salario de un congresista de estas características (línea 103), pero sí se justificaría si se tratara de personas ilustradas del siglo XIX (línea 23).

Esta creencia de asociar la "mala" escritura con un obstáculo para el progreso económico y social del país se enmarca dentro de las maneras en las que se ha percibido la escritura desde las TGD:

En efecto, muchas de las reflexiones provenientes de la 'gran división' son el sustento de influyentes mitos que se derivan de los postulados sobre las supuestas diferencias cognitivas y psicológicas entre poblaciones letradas e iletradas y sobre el impacto que esto debería tener en el desarrollo económico y social de los pueblos (Vich y Zavala, 2004, p. 44).

Así, en las formas de concebir la escritura, Correo da por sentado que la congresista no es apta para legislar y se la representa como un sujeto opuesto y enfrentado al progreso, pues está a la "defensiva" y es 
"prejuiciosa" (líneas 134, 135, 136, 139), descalificativos con los cuales se buscaba desprestigiar la imagen política de Supa, debido a su nivel de instrucción o educación bajo, "elemental" (línea 128). Al respecto, las TGD consideran que el pensamiento letrado es superior al pensamiento oral, que es precisamente lo que hace el diario al situarla como iletrada (líneas 27, 84), pues como su castellano no es el estándar, la asumen como incivilizada y, por tanto, como símbolo del atraso económico de un país. Para el diario, ella no posee una "buena educación", porque tiene una instrucción "elemental” (línea 128).

Así mismo, al analizar las manifestaciones del diario, la relación causa-efecto entre la escritura y el desarrollo del progreso social o político (por ejemplo, la aprobación de leyes) se expresa como una generalización (línea 5, 80,91), igual que lo que ocurre con la expresión "es indiscutible" (línea 128), la cual naturaliza la forma de asumir esta consecuencia. De este modo, "la instrucción elemental" (línea 128) reduce la capacidad que tiene la congresista para elaborar leyes, lo que queda evidenciado por el adverbio "poco" (línea 130) y se niega su posibilidad para aportar con la reflexión de la política diaria. La metáfora de formar parte de "la nave del Estado" (línea 131) revela que la congresista no sería una tripulante acorde con las expectativas de la élite social que dirige el Estado, no puede tomar el timón y ni siquiera iría en la misma dirección que el resto de los marineros. Este juego retórico invisibiliza la presencia de los congresistas, incluso limeños, que carezcan de prácticas de redacción para elaborar un proyecto ley o usar siempre las reglas de la ortografía estándar, lo cual es contradictorio pues, como es sabido, hay congresistas que tienen sus propios asesores dedicados a formular los proyectos legislativos.

Por otra parte, con el adverbio "así" en "una persona así" (línea 132), se engloban y manifiestan valoraciones claramente negativas, pues esta partícula en el discurso del diario se presenta con una connotación peyorativa y de reproche. En relación con ello, si bien en el diario se usa el adverbio "posiblemente" (línea 132) para atenuar alguna conclusión, indica con mayor énfasis la idea de con frecuencia va "a oponerse", a estar en contra (línea 133); es decir, se refuerza la imagen obstructiva que Supa genera al continuar siendo representante legislativa en el Congreso y resistirse desaparecer o ser purgada. Para Correo, como se ve, la falta de desarrollo económico y social se transfiere, pues, 
a la supuesta incapacidad de la congresista quien "no sabe" escribir y que estaría a la "defensiva" ante cualquier idea nueva. La congresista Supa es percibida una vez más como "ignorante" (línea 140) e, incluso, "ubicada en una posición anacrónica" (línea 143). El término "prejuiciosa" la descalifica (línea 135), considerándola como una persona cuyas opiniones se forman sin conocimiento alguno o responden a decisiones inmotivadas, convirtiéndose en una intrusa dentro del Congreso (línea 142), que detiene el trabajo de este organismo (línea 144) y, en última instancia, al avance sociopolítico del país (líneas 149, 150). Su ortografía para el diario es evidentemente perniciosa para la sociedad, lo cual se ve apoyado por la postura crítica de la excongresista al Tratado de Libre Comercio con Estados Unidos, por lo cual Correo desde entonces la ha visto como opositora al libre comercio y al progreso económico (líneas 5, 80, 91).

En cuanto a la asociación entre la escritura de la congresista y el no ser apta para legislar (línea 130) Correo solo se fija en aspectos técnicos de la escritura y exagera los elementos negativos con bastante detalle (línea 41), lo que demuestra que no existe una visión amplia referida a la literacidad, es decir, de las escrituras relacionadas con propósitos y contextos específicos y formas de acercarse a ella. Lo que produce y reproduce el diario es la manera de establecer desigualdades entre los individuos (líneas 86, 86, 89): unos son más aptos para gobernar, mientras que otros lo son para ser gobernados; los que tienen "educación" y "saben escribir" son miembros legítimos para legislar, los otros para ser mandados (líneas 151, 158).

Los supuestos que se producen y reproducen acerca de los hablantes y escribientes del castellano andino por periódicos como Correo continúan en boga dentro de nuestra sociedad y se encuentran arraigados en las maneras en que se considera la escritura en la enseñanza escolar y universitaria. Lo que hace el diario es, entonces, apoyar el proyecto educativo y la visión cultural bajo el modelo autónomo, donde las culturas andinas y nativas en general no tienen cabida, y no solo sus formas de hablar, sino su presencia o la aceptación de sus hablantes. Por eso, una estrategia del diario para apoyar su idea de que la escritura es necesaria para legislar es la intertextualidad: recurre a citas de autoridades "académicas" vistas como neutrales para ajustarlas a su propia línea argumentativa (líneas 42, 43, 50, 51, 61, 62). 
Después de la nota del diario del 17 de abril del 2009, el Pleno del Congreso condenó la actitud de Correo al haber publicado información privada de la congresista Hilaria Supa usada para infravalorarla. El comunicado fue aprobado por 72 votos a favor, dos en contra y una abstención. Los excongresistas Aurelio Pastor del Partido Aprista (APRA) y Martha Hildebrandt de Alianza por el Futuro (AF) votaron en contra (línea 199). Para Pastor, el diario matutino solo se limitó a expresar su preocupación por la "calidad de la representación en el Perú" (BBC, 2009), mientras que para la lingüista y exlegisladora Hildebrandt el diario solo informó, ya que para ella Hilaria Supa podría ser quechuahablante y escribir un correcto castellano, por lo que entonces no le hubiesen tomado las faltas de ortografía que tiene (El Universo, 2009). Es decir, para ambos exparlamentarios si Supa hubiera escrito en castellano estándar, no habría sido discriminada ni se habría convertido en noticia nacional ni mundial. Con ello se aprecia que el modo de asumir la escritura desde el modelo autónomo está tan internalizado, incluso entre las autoridades políticas, que estas terminan por apoyar la idea de que legislar implica tener buena ortografía.

Correo, asimismo, deslegitimó a todo el resto de los congresistas señalando que no sabían leer o comprender (línea 172) y los asumió como patéticos (línea 198). Al principio, sostuvo que estos no sabían escribir, pero como estuvieron en contra de sus formas de pensar, ello demostraba que al parecer todos tendrían problemas de escritura y sobre todo de lectura, pues no lograron entender su postura (línea 167). Esta es una estrategia de los discursos situados en el modelo autónomo, donde si los otros no piensan como uno, entonces ello es indicativo de que se tienen problemas de comprensión de lectura, con lo cual se representa al otro como iletrado o analfabeto, al no compartir su lectura de los hechos, sino evidenciar una postura distinta. Desde esta perspectiva, los productores del discurso buscan alimentar siempre a sus lectores y sus consumidores, por tanto, deben asumir la forma de pensar vertida en el discurso, sin oponerse para no terminar siendo situados como enemigos, carentes de inteligencia, intelecto o sabiduría, y como apañadores del supuesto "retraso" económico y social del país (línea 200, 201, 202, 203, 204).

Las dos representaciones hasta aquí analizadas alimentan el discurso acerca de la literacidad desde el enfoque de las TGD, el cual ha 
sido relacionado por el periódico Correo con ideas de raza y educación, vínculo que conduce finalmente a reproducir un discurso racista.

\subsection{Ortografía y racismo}

Previamente hemos podido observar la desaprobación de la ortografía de la congresista Supa por parte de Correo, sobre la base de asunciones relacionadas con el modelo de la gran división respecto de qué es la escritura y de cómo el pensamiento letrado es cognitivamente superior e inclinado al progreso o a la civilización.

En este contexto cabe preguntarnos si el discurso formulado por Correo acerca de la ortografía de Supa es racista (van Dijk, 2005) y, en consecuencia, si es una manifestación de los discursos raciales peruanos (Callirgos, 1993). De acuerdo con De la Cadena (1998), en la actualidad el racismo no se evidencia abiertamente, la gente no explicita la racialización hacia la piel, sino más bien lo hace por medio de una nueva forma de discriminación que denomina "racismo silencioso", como una forma de exclusión basada en la inteligencia y la educación: lo que opera entonces en el discurso de Correo es un discurso racista silencioso.

Así, el diario Correo no deja de hacer alusión a la "mala" escritura de la congresista Supa asociada con la falta de educación, capacidades cognitivas y aptitudes políticas, categorías que se usan en las prácticas de racialización solapadas. Según Zavala y Zariquiey (2007): “hoy, en Perú, el racismo se ha articulado con las categorías de clase, cultura y educación" (p. 334). Estos autores sostienen que la educación se vincula directamente con el aprendizaje de la lectoescritura, por ello en el Perú la falta de educación ha sido asociada con la persona analfabeta que en este país se posiciona "como el ser más despreciado y más discriminado de todos, incluso más que el indio o que el pobre (aunque sabemos que los analfabetos son, por lo general, indios y pobres)" (Zavala y Zariquiey, 2007, p. 366).

Estos mismos autores argumentan que en el Perú "los analfabetos son representados como 'ciegos', inmorales o indecentes de razonar con inteligencia (o con 'abstracción,' 'racionalidad' y 'lógica')” (Zavala y Zariquiey, 2007, p. 366). Desde esta perspectiva no escribir en la variedad estándar constituye un horror (línea 189), lo que sirve como justificación para discriminar y excluir a la gente, de modo que la or- 
tografía está siendo usada como un recurso de racialización, y no solo contra la congresista, sino también contra muchos peruanos que tienen como primera lengua una lengua indígena y como segunda lengua el español, particularmente contra los hablantes que han aprendido el español sin instrucción formal. De esta manera, las maneras de concebir la ortografía se convierten en una herramienta para segregar culturalmente a las personas "no educadas": a partir de la escritura se evalúan y miden las capacidades intelectuales, la escolaridad, el ejercicio político, la ética y la defensa de la democracia. Correo, por ejemplo, cita a dos entrevistados en uno de sus escritos, quienes sostienen que un congresista necesita no solo de ética, sino también de preparación, es decir, se exige un nivel de escritura. Incluso, después de agregar las opiniones respectivas, expone que la excongresista fue empleada doméstica o empleada de hogar (y menciona las provincias en las que trabajó) (línea 75). Es decir, no trata de registrar información "neutral" acerca de las carencias de Supa, sino que toma partido al racializarla o ningunearla.

En el Perú los hablantes se guían por el prejuicio de que solo las clases altas o bien posicionadas hablan y escriben correctamente, por lo que el resto de los ciudadanos que no lo hacen son criticados, pues no internalizan o memorizan las reglas del buen hablar y escribir, presentando déficits cognitivos asociados con su lugar de procedencia. Las clases favorecidas piensan que las reglas de la ortografía se incorporan de forma natural, mientras que para los que no lo son se trata de una experiencia cultural, que involucra el aprendizaje de un sistema de reglas que les es ajeno, nuevo, y que requiere entrenamiento.

Paradójicamente, aunque los hablantes bien posicionados cometan faltas ortográficas o no sepan escribir una palabra del castellano estándar, no son censurados ni discriminados, porque se trata del grupo más prestigioso de la sociedad peruana. Por ejemplo, Faverón (2009) analiza la sintaxis de Aldo Mariátegui, director del diario, quien evidentemente comete errores gramaticales, como la discordancia verbal y temporal y subraya que:

estoy completamente convencido de que no hay conclusiones que se puedan sacar sobre la inteligencia de una persona a partir de su sintaxis. Imagino que a Mariátegui le conviene aceptar, de ahora en adelante, esta misma premisa. No vaya a ser que le pidan 
satisfacer un nivel mínimo de sintaxis culta para dirigir un diario (párr. 17).

En efecto, los errores sintácticos de Aldo Mariátegui no fueron noticia, ya que por su posición social, sus escritos no escandalizan, aun cuando dirija uno de los diarios más populares del Perú y, además, uno de los noticieros más importantes del país, en el canal Frecuencia Latina. Dentro de este grupo, también puede haber limeños que hablen y escriban "mejor" el inglés como su segunda lengua que el español como su primera lengua, pero igualmente son perdonados o socialmente aceptados. Sin embargo, esto no ocurre con los hablantes andinos, a los que se les racializa o separa de la sociedad, porque se les asocia con una pronunciación indebida o confusiones en el "buen hablar". Esto contrasta con el caso de las confusiones ortográficas de personas que han asistido por varios años a la escuela y han llegado a estudiar en la universidad. A estos sujetos se los disculpa por cometer errores de ortografía y no se los penaliza como sucede con los hablantes que, de antemano, han sido jerarquizados en posiciones sociales inferiores, como ocurre con los hablantes andinos. A Supa, por ejemplo, se la condena por escribir "situasión" y "participasión” (línea 31). En términos raciales, si el error ortográfico es cometido por una persona de procedencia andina, que es mujer, y que carece de escolaridad, ello resulta muy reprochable (Secretaría de la Mujer-Confederación Nacional de Comunidades del Perú Afectadas por la Minería, CONACAMI y Programa de Mujer IndígenaAsociación Interétnica de Desarrollo de la Selva Peruana, AIDESEP, 2009), más que si se tratara de una mujer costeña o hasta de un hombre andino. En el Perú, la mujer andina está más infravalorada que el hombre andino, quien se ha mimetizado con la sociedad occidental en sus formas de hablar, vestir y convivir y, por ello, es percibido más cercano a la modernidad, mientras que a las mujeres andinas se les asocia como banalmente resistentes de sus culturas ancestrales. Así, la televisión peruana suele satirizar a la mujer andina como "necia", "pobre", "mal vestida" y "con mal hablar", en personajes como la Paisana Jacinta (De los Heros, 2016, Turpo y Gutiérrez, 2019, Comisión Nacional contra la Discriminación, 2019). En el caso de Supa debe quedar claro que está siendo discriminada como congresista y como hablante, ya que al igual que su otrora excompañera quechua-hablante puneña María Sumire - autora de la Ley de Lenguas aproba- 
da en el año 2011, primera ley que defiende los derechos lingüísticos de las lenguas originarias en el Perú-, está siendo vista como una hablante racialmente imperfecta, incompleta e intrusa (líneas 1, 4, $5,6,7,11,15,25,26,27,148)$, a pesar de que las faltas de ortografía no han bloqueado su comunicación, pues ella recoge la información que busca registrar o usar.

Pese a lo anterior, para Correo no se puede perdonar que una persona pública como la exparlamentaria Supa escriba de tal manera, pues la considera como alguien "sin cultura" o "sin educación" (línea 217). Este tipo de higiene verbal se produce y reproduce generalmente en los manuales y adeptos de la gramática normativa o gramática prescriptiva. Un caso de este discurso es el de Gómez (2007) quien señala que

al lado de incorrecciones crasas solo detectables en capas sociales de poca cultura, aparecen otras relativamente frecuentes, más discutibles e, incluso, discutibles en las que suelen incurrir personas más o menos cultas y de gran proyección pública dada su profesión u oficio (locutores, periodistas, políticos) (p. 8).

O también es el de Sánchez (2016, párr. 2-6), quien sostiene en su post de Linked, titulado "Escribir correctamente da una muy buena imagen a los profesionales", que "Escribir correctamente es nuestra carta de presentación ante los demás"; "La mala ortografía es una enfermedad de transmisión textual"; "todo lo que se llegue a plasmar a través de las palabras, es un indicativo de la personalidad de cada uno. Se refleja la educación, los valores y las costumbres, porque la escritura, simplemente, nos delata"; "No eres tú, es tu ortografía...”.

En este sentido, Correo en sus prácticas de desprestigio ha buscado desligarse de la responsabilidad de haber racializado a la congresista, para lo cual buscó construir la imagen de que ella se victimizaba y que el periódico de circulación nacional no discriminaba. Sin embargo, sus estrategias léxicas y retóricas son muestra de que este medio de comunicación intentó victimizarse al victimizar a la exparlamentaria (líneas 13, 14, 81, 97, 129, 140, 141, 142, 143, 188, 189, 190, 191, 192, 193, 194, 195, 106, 197, 206, 207, 208). En un país que es racista, nadie aceptará que discrimina, por lo que en su defensa el diario sostuvo que solo recogía una realidad (línea 227). Como se ha visto, muchas veces los ciudadanos, la prensa o el Estado no se dan cuenta de este tipo de 
acciones, pues está tan internalizado que se ve como algo común posicionarse racialmente uno sobre otro (línea 224, 225, 226, 227, 230, 231).

\section{Conclusiones}

Siguiendo a las TGD, la escritura está relacionada con capacidades cognitivas. En ese sentido, escribir bien implica un grado respetable y lógico de la organización del pensamiento y conocimientos para actuar en el mundo. Desde el ACD, las concepciones acerca de la escritura pueden generar prácticas de racialización, ya que las formas de apreciar determinadas escrituras responden a los posicionamientos sociales de las personas. De esta forma, los individuos más letrados pueden discriminar a los menos letrados y atribuirles características negativas o denigrantes, hasta impedirles su acceso al espacio público, educativo y político.

A partir del ACD hemos visto que el diario Correo reprocha la escritura de la congresista Supa sobre la base de la observación de errores ortográficos y la representa como un sujeto carente de capacidades cognitivas superiores. Para el diario, la escritura no hizo de Supa un individuo letrado y, más aún, como no escribe bien, ella no puede legislar, por ser percibida como un individuo no preparado, no apto y sin educación. Así, puesto que gobernar implica tener la capacidad para escribir bien, el individuo que escribe mal se convierte en un obstáculo para el desarrollo económico y social de un país.

El análisis del trabajo arrojó dos representaciones que derivan de las formas en que se considera la escritura. Las manifestaciones discursivas de Correo, asimismo, son muestras de los discursos producidos y reproducidos desde el enfoque del modelo autónomo sobre la literacidad. Hemos procurado deconstruir estas creencias sobre la base de los NEL, que perciben la escritura vinculada con objetivos y contextos específicos, o marcos de socialización particulares. De esta forma, en nuestro país los sistemas gráficos no son iguales para hablantes monolingües que para bilingües, donde el proceso de aprendizaje de la escritura se ve influenciado por muchos otros factores sociales, como por ejemplo el poder. Para estos nuevos estudios, la oralidad o la influencia de una lengua materna cobra importancia en el aprendizaje de un sistema hegemónico de escritura, pero no como una manera de desdeñar a los aprendientes, sino como una forma de observar el acer- 
camiento de ellos a este nuevo sistema que implica una serie de reglas y prescripciones impuestas (las cuales también pueden ser transgredidas por individuos letrados, pero que no son ubicados en la misma valoración social que los hablantes de lenguas indígenas, provenientes de zonas emergentes y que, a pesar de lograr un cargo político estatal, siguen siendo infravalorados).

Como hemos visto, la literacidad no solo involucra aspectos técnicos, sino otros elementos. Con los NEL se pueden valorar las notas personales de Supa, quien se apropia de la escritura, la recrea, la ve como un medio para satisfacer sus necesidades comunicativas, pues para ella lo que escribió tenía sentido. Los usos de lo letrado se sitúan en contextos sociales particulares donde tiene relevancia a través de los valores que subyacen en las prácticas letradas de los individuos (Street, 2000). En otras palabras, la literacidad se sitúa en contextos específicos y marcos culturales, involucra maneras y propósitos de acercarse a lo escrito y valora por igual los productos escritos entre los individuos (Calderón, 2015).

Las formas en que se perciben la escritura y la ortografía se han convertido en fuentes de discriminación o racialización en el Perú. La ortografía de la congresista Supa, por ejemplo, se percibe como degradante y una amenaza a la normatividad de la escritura castellana, negándosele su derecho a ser legisladora y a tomar decisiones políticas sobre la base de sus escritos. Alguien como ella no podría ser aceptada como presidenta del país, ya que el discurso racista argumentaría que sería un atentado. Las faltas de ortografía se convierten, por tanto, en herramientas para diferenciar a individuos: unos letrados, otros no; unos educados, otros no; unos críticos, otros no. De esta manera, se establecen jerarquías y desigualdades político-sociales.

A Paredes (2001) le parecía extraño que

Al volver a Perú, después de casi 18 años de ausencia, compruebo con sorpresa que los cholos (95\% de la población peruana), antes menospreciados y relegados, están a un paso del poder político, aunque este no pueda darse en un año o dos, ni quizá en cinco, estoy seguro, sin embargo, que no pasarán décadas para que este hecho de extrema importancia nacional, de absoluta necesidad histórica, sea real (p. 4). 
Estas expectativas siguen sin realizarse, ya que la sociedad peruana aún empodera más al individuo mejor situado socialmente y le resta legitimidad al que se encuentra en una posición social desfavorecida. No obstante, es pertinente explicar que las formas en que procedió la línea editorial de Correo deben entenderse y situarse, asimismo, como parte de las valoraciones sociales que se tienen de la escritura en sociedades occidentales diametralmente jerarquizadas; es decir, se trata de creencias que devienen de las prácticas y concepciones sociales tradicionales de lo que se considera la escritura. Dicho de otro modo, estas formas de pensar de Correo no son estrictamente privativas, exclusivas o particulares del periódico, sino de muchas personas, generalmente bien posicionadas en la sociedad peruana, e incluso latinoamericana, que valoran la literacidad desde el marco del modelo autónomo de la literacidad.

Finalmente, desde el ACD podemos señalar que no se trata necesariamente de individuos concretos que discriminan y desaprueban la falta de practicidad y efectos que "genera" la escritura, sino de formas de pensar que han calado en la sociedad por años y que permanecen aún en el imaginario social de la mayoría de los ciudadanos, la prensa, la escuela, el Ministerio de Educación, etc., que puesto que segregan, deben ser desterradas, empezando por las escuelas y las universidades que luchan por la justicia social a través del debate y la mirada crítica (Murillo, 2018).

\section{Referencias bibliográficas}

Ames, P. (2002). El esquivo encanto de la escritura. Un ensayo en torno a los estudios sobre literacidad. En P. Ames (Ed.), Para ser iguales, para ser distintos. Educación, escritura y poder en el Perú (pp. 63-84). Lima: Instituto de Estudios Peruanos.

Araníbar, A. (2012). Perú: la oportunidad de un nuevo ciclo de desarrollo. Escenarios prospectivos 2012-2016. La Paz - Bolivia: Programa de las Naciones Unidas para el Desarrollo (PNUD), Proyecto de Análisis Político y Escenarios Prospectivos (PAPEP-PNUD), Instituto Internacional para la Democracia y la Asistencia Electoral (IDEA Internacional).

Barton, D. y Hamilton, M. (2004). La literacidad entendida como práctica social. En V. Zavala, M. Niño-Murcia, y P. Ames (Eds.), Escritura y sociedad: nuevas perspectivas teóricas y etnográ- 
ficas (pp. 109-139) Lima: Red para el Desarrollo de las Ciencias Sociales en el Perú.

BBC (2009). Debate por "discriminación" lingüistica. Recuperado de https://www.bbc.com/mundo/america_latina/2009/04/090424_0201_peru_supa_discriminacion_rb

Braslavsky, B. (2003). ¿Qué se entiende por alfabetización? Lectura y vida. Revista Latinoamericana de Lectura, 24(2), 1-17. Recuperado de https://www.oei.es/historico/n9621.htm

Calderón, M. (2015). Producción escrita y literacidad familiar. Literatura y Lingüistica, 32, 259-282. https://doi. org/10.29344/0717621X.32.1512

Calderón, R. (2009). Hilaria Supa: Recuento de insultos y ofensas de Correo a los aimaras y quechuas. Recuperado de http://www. losandes.com.pe/oweb/Nacional/20090426/21369.html

Callirgos, J. (1993). El racismo. La cuestión del otro (y de uno). Lima: Centro de Estudios y Promoción del Desarrollo (DESCO).

Cerrón-Palomino, R. (2003). Castellano andino. Aspectos sociolingüísticos, pedagógicos y gramaticales. Lima: Pontificia Universidad Católica del Perú (PUCP) y Deutsche Gesellschaft für Internationale Zusammenarbeit (GTZ).

Cervera, Á. (2016). Marcas lingüístico-discursivas en titulares de prensa en español actual. Literatura y Lingüística, 34, 265-294. https://doi.org/10.29344/0717621x.34.1448

Comisión Nacional contra la Discriminación (2019). Informe sobre la discriminación en medios de comunicación en el Perú, con especial énfasis en la discriminación étnico-racial. Lima: Ministerio de Justicia y Derechos Humanos. Recuperado de https://cdn.www.gob.pe/ uploads/document/file/297520/Informe_CONACOD_ Discriminaci\%C3\%B3n_Medios.pdf

Correo (23 de abril de 2009a). Supa no supo. Recuperado de https:// diariocorreo.pe/opinion/supa-no-supo-142081/

Correo (17 de abril de 2009b). ¡Qué nivel! Urge Coquito para congresista Supa. En Arte Nuevo. Repudio público al diario Correo, su director Aldo Mariátegui y a su pensamiento fascista, discriminador, canalla y vulgar. Recuperado de http://artenuevo.blogspot.com/2009/04/repudio-publico-al-diariocorreo-su.html 
De la Cadena, M. (2014). El racismo silencioso y la superioridad de los intelectuales en el Perú. En C. Hünefeldt, C. Méndez, y M. De la Cadena (Eds.), Racismo y etnicidad (pp. 54-98). Lima: Ministerio de Cultura.

De los Heros, S. (2016). Humor étnico y discriminación en La paisana Jacinta. Pragmática Sociocultural, 4(1), 74-107. https://doi. org/10.1515/soprag-2015-0011

El Universo (2009). Polémica en Perú por faltas ortográficas de legisladora indígena. Recuperado de https://www. eluniverso.com/2009/04/24/1/1382/9F3873442A594D8598 F0C47C8385F2FA.html

Fairclough, N. (1995). Critical discourse analysis: The critical study of language. London y New York: Longman.

Faverón, G. (2009). 7 ensayos de interpretación semántico-sintáctica. Mariátegui y el problema del perro que se muerde la cola. Recuperado de http://puenteareol.blogspot.com/2009/04/7ensayos-de-interpretacion-semantico.html

Fishman, A. (2004). Etnografía y literacidad: aprendizaje en contexto. En V. Zavala, M. Niño-Murcia y P. Ames, (eds.) Escritura y sociedad. Nuevas perspectivas teóricas y etnográficas (pp. 275290). Lima: Red para el desarrollo de la Ciencias Sociales en el Perú.

Garatea, C. (2010). Tras una lengua de papel. El español del Perú. Lima: Pontificia Universidad Católica del Perú.

Gómez T. L. (2007). Hablar y escribir correctamente. Gramática normativa del español actual (segunda edición). Madrid: Arco/ Libros.

Hildebrandt, M. (2013). Toledo habla de una forma prepotente $y$ malcriada. Recuperado de https://www.youtube.com/ watch?v=Rqx8sk6Kc04

Jiménez, P. y Lovón, M. (2015). Literacidad y etnografía: la escritura generada en los mercados comerciales. Lengua y Sociedad. Revista de Lingüística Teórica y Aplicada, 25(2), 92-106. Recuperado de http://revista.letras.unmsm.edu.pe/index.php/ ls/article/view/381

La República (03 de septiembre de 2005). Martha Hildebrandt: "Yo soy asquerosamente racional". Recuperado de https://larepublica.pe/archivo/297834-martha-hildebrandt-yo-soy-asquerosamente-racional/ 
La República (31 de julio de 2001). Toledo entre la esperanza y una decepción más. Recuperado de https://larepublica.pe/ politica/323237-toledo-entre-la-esperanza-y-una-decepcion-mas/

Leodent (2009). Congresista Hilaria Supa no sabe escribir correctamente. Recuperado de https://www.forosperu.net/temas/ congresista-hilaria-supa-no-sabe-escribir-correctamente.57146/pagina-2

Lovón, M. (2019a). El 'ciudadano' amazónico en el discurso oficial. Lingüística y Literatura, 75, 38-61. https://doi.org/10.17533/ udea.lyl.n75a02

Lovón, M. (2019b). Las palabras compuestas en el aimara de Conima. Lexis, 43(1), 55-85. https://doi.org/10.18800/ lexis.201901.002

Lovón, M. (2016). Enseñanza de la lengua vernácula como segunda lengua: lenguas indígenas peruanas en estado de L2. Escritura y Pensamiento, 19(38),185-210. Recuperado de https:// revistasinvestigacion.unmsm.edu.pe/index.php/letras/article/view/13707

Muñoz, P. (14 de mayo de 2015). Discriminación lingüística o "la forma correcta de hablar". Lamula.pe. Recuperado de https:// lamula.pe/2015/05/14/discriminacion-linguistica-o-la-forma-correcta-de-hablar/pavel/

Murillo, F. (2018). ¿De qué hablamos cuando hablamos de justicia social en educación?: análisis ideacional como estrategia de análisis crítico del discurso. Literatura y Lingüística, 37, 273300. https://doi.org/10.29344/0717621X.37.1384

Olson, R. D. (1998). El mundo sobre el papel. El impacto de la escritura y la lectura en la estructura del conocimiento. Barcelona: Gedisa.

Ong, W. (1997). Oralidad y escritura. Tecnologías de la palabra. Buenos Aires: Fondo de Cultura Económica.

Paredes, R. (2001). Los cholos y el poder (sexta edición). Lima: Pies de plomo.

Pérez, J. (2004). Los castellanos del Perú. Lima: Proeduca y Deutsche Gesellschaft für Internationale Zusammenarbeit (GTZ).

Pérez, J., Acurio, J. y Bendezú (2008). Contra el prejuicio lingüístico de la motosidad. Un estudio de las vocales del castellano andino 
desde la fonética acústica. Lima: Instituto Riva-Agüero (IRA) y Pontificia Universidad Católica del Perú (PUCP).

Pérez, J. y Zavala, V. (marzo, 2010). Aspectos cognitivos e ideológicos del motoseo en el Perú. Trabajo presentado en V Congreso Internacional de la Lengua Española. Centro Virtual Cervantes, Valparaíso.

Prensa Libre (2009). Caso de congresista indigena reflota tema de racismo y educación en Perú. Recuperado de http://medios.mugak.eu/noticias/noticia/198986

Scribner, S. y Cole, M. (2004). Desempaquetando la literacidad. En V. Zavala, M. Niño-Murcia, y P. Ames, (Eds.), Escritura y sociedad. Nuevas perspectivas teóricas y etnográficas (pp. 57-79). Lima: Red para el desarrollo de la Ciencias Sociales en el Perú.

Sebba, M. (2009). Spelling and Society: The Culture and Politics of Orthography around the World. Lancaster: Cambridge University Press.

Rockwell, E. (2000). La otra diversidad: historias múltiples de apropiación de la escritura. DiversCité Langues, 5, 1-12. Recuperado de http://www.teluq.uquebec.ca/diverscite

RPP (28 de mayo de 2013). Martha Hildebrandt analiza el lenguaje de Alejandro Toledo. Recuperado de https://rpp.pe/lima/ actualidad/martha-hildebrandt-analiza-el-lenguaje-de-alejandro-toledo-noticia-599035?ref=rpp

Sánchez, J. (2016). Escribir correctamente da una muy buena imagen a los profesionales. Recuperado de https://www.linkedin. $\mathrm{com} /$ pulse/escribir-correctamente-da-una-muy-buenaimagen-los-s\%C3\%Alnchez-morz\%C3\%Aln/

Secretaría de la Mujer-Confederación Nacional de Comunidades del Perú Afectadas por la Minería, CONACAMI y Programa de Mujer Indígena-Asociación Interétnica de Desarrollo de la Selva Peruana, AIDESEP (2009). Basta de racismo y discriminación contra las mujeres indígenas del Perú. Recuperado de https://bit.ly/2yfcTRF

Street, B. (1993). Cross-cultural approaches to literacy. Cambridge: Cambridge University Press.

Street, B. (1995). Social literacies: Critical approaches to literacy in ethnography and development. Nueva York: Longman. 
Street, B. (2000). Literacy events and literacy practices: Theory and practice in new literacy studies. En M. Jones y K. Jones (Eds.), Multilingual literacies: Reading and writing different worlds (pp. 17-30). Amsterdam/Philadelphia: John Benjamins Publishing Company.

Turpo, O. y Gutiérrez (2019). Racismo en la televisión peruana: ¿qué mensajes trasmiten los programas cómicos? Revista Universidad y Sociedad, 11(4), pp.184-192. Recuperado de http://scielo.sld.cu/scielo.php?script=sci_arttext\&pid $=$ S2218-36202019000400184

van Dijk, T. (2005). Ideología y análisis del discurso. Utopía y Praxis Latinoamericana. Revista Internacional de Filosofía Iberoamericana y Teoría Social, 29, 9-36. Recuperado de https://dialnet.unirioja.es/descarga/articulo/2734720.pdf

Vich, V. y Zavala, V. (2004). Oralidad y poder: herramientas metodológicas. Bogotá: Grupo Editorial Norma.

Vigil, N. (2010). Por primera vez una quechua-hablante fue designada presidenta de una comisión del Congreso. Recuperado de https://nilavigil.com/2010/08/11/por-primera-vez-unaquechuahablante-fue-designada-presidenta-de-una-comision-del-congreso/\#more-3161

Wodak, R. y Meyer, M. (Comps.). (2003). Métodos de análisis crítico de discurso. Barcelona: Gedisa Editorial.

Zavala, V. (2001). Vamos a letrar nuestra comunidad: reflexiones sobre el discurso letrado en los Andes peruanos. En S. López Maguiña (Ed.), Estudios culturales. Discursos, poderes, pulsiones (pp. 233-252). Lima: Red para el Desarrollo de las Ciencias Sociales en el Perú.

Zavala, V. (2002). (Des)encuentros con la escritura: escuela y comunidad en los Andes peruanos. Lima: Red para el Desarrollo de las Ciencias Sociales en el Perú.

Zavala, V. (1999). Reconsideraciones en torno al español andino. Lexis, 23(1), 25-85. Recuperado de http://revistas.pucp.edu.pe/index.php/lexis/article/view/7256

Zavala, V. y Córdova, G. (2010). Decir y Callar: lenguaje, equidad y poder en la universidad peruana. Lima: Pontificia Universidad Católica del Perú (PUCP).

Zavala, V. y Zariquiey, R. (2007). Yo te segrego a ti porque tu falta de educación me ofende: una aproximación al discurso racista 
en el Perú contemporáneo. En T. Van Dijk (Coord.), Racismo y discurso en América Latina: una introducción (pp. 333370). Barcelona: Gedisa. 


\section{Anexos: El corpus}

A continuación, se registran los escritos que hicieron referencia a Hilaria Supa en Correo.

\section{(a) Fragmento de la columna editorial del 16 de marzo de 2006}

1. Ya, ya, están Torres Caro, Nancy Obregón, 2. las disforzadas Sumire y Supa, 3. que juegan siempre a las víctimas.

\section{(b) Fragmento de la columna editorial del 10 de abril de 2007}

4. Pues allí tienen a la congresista Hilaria Supa 5. saboteando el TLC en su etapa más crucial, 6. con cartas que adivino no ha escrito 7. (demasiado bien redactadas). 8. Le importan un bledo los empleos que crearía 9. y la vital inversión que atraería.

(c) Fragmento de la columna editorial del 21 de febrero de 2008

10. Sugiero un minuto de silencio por el tino de nuestros congresistas 11. y dos minutos de silencio por las neuronas de la congresista Sumire, 12. quien fue la autora de la genial y pertinente iniciativa 13. (vaticino su respuesta: "racista" o alguna sandez así. 14. De eso vive políticamente, 15 . junto a su yunta la Supa).

(d) Fragmento de la columna editorial del 4 de marzo de 2009

16. Ya tuvimos este sistema de renovación parcial durante la huachafamente llamada "República Aristocrática" (1895-1919) 17. y fue un fracaso, 18. con problemas eternos 19. (como la fallida prórroga arbitraria en 1910 del tercio que debía cesar en 1911) 20. en Congresos que encima eran infinitamente superiores a los actuales 21. al ser integrados por unos señorones muchísimo más cultos 22. y preparados 23. (el destacado filósofo Javier Prado 24. o jurisconsultos de nota como Mariano H. Cornejo, Francisco Tudela y Varela, Alberto Ulloa, Arturo Osores, J. Matías Manzanilla, entre otros) 25. que los actuales tan penosos como Yonhy Lescano, Supa, Sumire, Sasieta, Cajahuanca, Miró Ruiz, Otárola, Mekler, Abugattás, etc. 26. No existe el menor punto de comparación entre esos eruditos de antaño 27. y estos iletrados que tenemos ahora. 
(e) Titular y subtitular de la portada del 17 de abril de 2009

28. Urge 29. Coquito para congresista Supa

30. ¡Qué nivel!

(f) Notas personales de Hilaria Supa fotografiadas por un lente teleobjetivo y publicadas en la portada o primera plana del 23 de abril de 2009

31. Jueves De abril-16-2009 Pleno Del comgreso De la rePoBleca si Discotio lasituasion de Brai ovo Muchas ParticiPasion custo (...) NoPresencia Del preme menistro para (...) subre Bray subreatentado (...) pindio el pleno vernes De abril 172009

\section{(g) Titular y columna editorial del 17 de abril de 2009}

32. La congresista no tiene quien le escriba

33. Mientras el país estaba pendiente de las explicaciones que brindaba al pleno del Congreso 34. el premier Yehude Simon sobre la brutal emboscada terrorista que acabó con la vida de 14 soldados en la zona del VRAE (Valle del Río Apurímac-Ene), 35. una diligente congresista 36. -cual eficiente estudiante tomaba apuntes del asunto.

37. Se trataba de Hilaria Supa, 38. parlamentaria del Partido Nacionalista Peruano elegida por la región Cusco, 39. y a decir de lo que descubrió una reveladora foto de Correo, 40. sus limitaciones en cuanto a ortografía y sintaxis dejan mucho que desear. 41. Las tomas obtenidas del cuaderno de notas de la mujer de 49 años hablan por sí solas.

42. Para el secretario técnico de la Asociación Civil Transparencia, Percy Medina, 43. el caso de Supa es una muestra del nivel de responsabilidad que tienen los partidos políticos 44 . al proponer a sus electores los candidatos idóneos para los cargos que aspiran ocupar. 45. "Los partidos políticos son los únicos autorizados a presentar listas de candidatos (al Congreso), 46. y son el filtro que tendría que garantizar su identidad, calidad, trayectoria y formación ética. 47. Es su responsabilidad proponer a los electores personas que tengan la trayectoria personal y política 48. que les permita interpretar lo que quiere la gente que se fiscalice y legisle", indicó.

49. Cualquiera, no. 
50. Medina enfatizó además 51. que es primordial que los partidos políticos se aseguren de que aquellas personas que proponen para algún cargo público se encuentren debidamente preparadas. 52. "No solamente se requiere preparación en el sentido de instrucción, 53. sino también la ética es clave. 54. Un partido político - antes de presentar su lista- tiene que estar seguro de que las personas que está presentando tienen una trayectoria de honestidad, de compromiso... 55. No se puede presentar a cualquiera", opinó. 56. En ese sentido, Medina consideró 57. que los partidos políticos —al evaluar a sus candidatos - no deben caer en criterios de selección 58. como el nivel de popularidad o de aporte económico a la campaña electoral. 59. "Fíjese que muchos partidos que obtuvieron muchas curules (en las últimas elecciones congresales), luego las perdieron porque sus candidatos no compartían su visión programática", acotó.

60. Bancada debe apoyarla.

61. Por su parte, el director ejecutivo de Reflexión Democrática, José Élice, 62. dijo que Supa —más allá de su condición de quechuahablante-63. tiene derecho a ocupar un cargo político. 64. No obstante, agregó que era responsabilidad de su partido 65. - y sobre todo de su bancada - 66. asesorarla y apoyarla en la revisión de la estructura 67. y el fondo de los proyectos que presente. 68. "Puede haber personas que escriban pésimo, 69. pero que pueden dar aportes bien interesantes 70. o que conocen otras realidades que todos no conocemos. 71. Y tienen todo el derecho de participar en el Congreso. 72. Si no respetamos ese derecho, 73. estaríamos hablando de un Congreso elitista, 74. académico", acotó.

75. Fue empleada del hogar

76. Muchos años antes de ser elegida congresista, 77. Hilaria Supa se desempeñó como empleada del hogar en el Cusco, Arequipa y Lima. 79. Días previos a su juramentación como legisladora, 80. la nacionalista irrumpió en el hemiciclo del Congreso para protestar contra el TLC suscrito con EE.UU. 81. Además, protagonizó un escándalo al denunciar haber sido víctima de discriminación por la aerolínea Iberia. 82. Tiempo atrás, su colega Martha Hildebrandt 83. se quejó de sus destempladas protestas sobre un proyecto para declarar oficiales las lenguas aborígenes. 84. "Miren los modales de estas niñas quechua-hablantes", comentó. 
85. Un trabajo muy flojo

86. Si bien el portal del Congreso revela que Hilaria Supa tiene registrados 43 proyectos de ley en la presente legislatura 2008-2009, 87. casi todos han sido suscritos colectivamente por la bancada del Partido Nacionalista.

88. De acuerdo con el registro consultado por este diario, 89. Supa solo ha presentado dos proyectos con autoría propia, 90. como son la Ley General de Sanidad y la norma que propone crear la Comisión de Administración de bienes del Colegio Nacional de Ciencias del Cusco.

91. En su haber figuran además proyectos derogatorios de importantes normas que el Ejecutivo formuló en mérito a las facultades para legislar en materia del Tratado de Libre Comercio con Estados Unidos.

(h) Titular y columna editorial del 23 de abril de 2009

92. Supa no supo

93. - Todos estos cambios en el tránsito con respecto a los conductores borrachos van a fracasar si no se modifica el actual límite de alcohol de $0,5 \%$, absurdamente bajo y que curiosamente fue cambiado por Toledo. 94. Se debe volver al cuerdo 0,75\% anterior o, mejor aún, adoptar el 0,8\% yanqui. 95. Los ministros Cornejo y Fernández están cometiendo un yerro monumental al no fijarse en este importantísimo detalle.

96. - Pongo el parche... 97. No nos anima ningún ánimo peyorativo, excluyente, racista, clasista, costeñista, anti-indigenista, etc. contra la congresista humalista Hilaria Supa. 98. Esto que quede claro, 99. pues lo "políticamente correcto" se está volviendo asfixiante en nuestro país. 100. Y que quede claro también que más bien nos provoca pena 101. que esta humilde mujer 101. tenga esas carencias 102. y no queremos hacer ninguna befa con ello. 103. Pero no se puede pagar más de S/. 20 mil al mes 104. y darle tanto poder y responsabilidades 105. a quienes no están mínimamente iluminados por las luces de la cultura. 106. Pues aquí lo que se pone realmente en debate es si es sano para el país 107. que pueda acceder al Congreso alguien con un nivel cultural tan bajo, 108. cuya ortografía y 
gramática revelan serias carencias 109. y sin aparente ánimo de enmienda, 120. porque no me digan que no es evidente 121. que Supa rara vez agarra un libro, 122. ya que está probado que la gente que lee poco 123. es la que peor escribe 124. al estar menos familiarizada con las reglas más elementales de redacción. 125. Nadie pide que cada congresista sea una Martha Hildebrandt, 126. pero, por Dios, 127. tampoco pueden escribir peor que un niño de ocho años. 128. $Y$ es indiscutible que una persona con una instrucción tan, digamos, elemental 129. - siendo generosos- 130. poco puede aportar en la elaboración de leyes, en la fiscalización de casos complejos, 131. en la reflexión diaria de hacia dónde debe ir la nave del Estado... 132. Una persona así posiblemente solo se va a limitar a repetir lugares comunes, 133. a oponerse a todo solo por oponerse, 134. a estar a la defensiva ante cualquier idea nueva, 135 . a ser prejuiciosa, 136 . a buscar llamar la atención mediante el escándalo 137. antes que por la excelencia de sus iniciativas, 138. a descalificar al adversario con el eterno recurso de victimizarse, 139. a ser agresiva... 140. Lamentablemente, todo lo anterior ha caracterizado a la congresista Supa 141. y estoy seguro de que su respuesta consistirá en acusarnos de ser nazis y hacerse la víctima. 142. No estamos en contra de que las personas elijan a congresistas con quienes se identifiquen, 143. pero tampoco se puede ir a extremos 144. y menos dejar de lado el mérito académico y la preparación. 145. Por eso el voto debe ser voluntario 146. y además debe haber requisitos extras para ser congresista, 147. como grado universitario 148. (aunque... ¿cómo escribirá la congresista humalista y abogada María Sumire?). 149. Si no, vamos a acabar en una oclocracia, como los griegos denominaban a la degeneración de la democracia. 150. Miren nomás a Bolivia...

151. Observo bloquear carreteras a los guías cusqueños de turismo 152. y no puedo menos que sonreír ante su supuesta sapiencia exclusiva, 153. pues pretenden que nadie más 154 . —ni siquiera la historiadora María Rostworowski ni los arqueólogos Walter Alva o Ruth Shady - puedan guiar turistas. 155. Ya están como el SUTEP, 156. que no permitiría que ni siquiera Vargas Llosa dicte clases de Literatura. 157. Además, si algunos hablan gruesas barbaridades son muchos de estos supuestos "guías", 158. charlatanes 159. que cuentan cualquier cosa sobre las ruinas 160 . y que hacen gala a me- 
nudo de un odio xenofóbico contra todo lo español 161. y un ensalzamiento superlativo de lo quechua 162. que linda con lo ridículo. 163.¡Viva Lugo carajo! 164. jJa, ja, ja! 165. ¡Qué tipo!

\section{(i) Titular y columna editorial del 24 de abril de 2009}

166. Comprensión de lectura

167. Hasta ayer creía que era un serio problema para la calidad de nuestro Legislativo que existan congresistas que apenas saben escribir. 168. Lamentablemente, 169. el asunto es más serio, 170. porque ayer el $90 \%$ de los que participaron en el debate sobre Supa demostraron 171. - si es que se tomaron el trabajo de leer antes el editorial y el artículo referidos al hecho- 172. que muchos de ellos no tienen una adecuada comprensión de lectura. 173. En ambos textos advertíamos que tocábamos el tema porque nos preocupa que el bajo nivel intelectual del Congreso 174. dañe tanto a nuestra democracia 175. (somos uno de los países latinoamericanos que menos creemos en ella. 176. Ver si no el Latinobarómetro) 177. y origine que este tenga una eterna desaprobación, 177. y que incluso sea visto con desprecio y burla por los ciudadanos. 178. Creemos que gente que tiene tanto poder y responsabilidades, 179. amén de ganar más de $\mathrm{S} / .20 \mathrm{mil}, 180$. debe tener una instrucción mínima.

181. Como remedio, 182. sugeríamos que se exija un grado académico 183. y que se instaure el voto voluntario 184. (nos faltó agregar que se decida el fin del voto preferencial). 185. Incluso buscamos dos opiniones contrapuestas: 186. la del experto de Transparencia Percy Medina (a favor) 187. y la de José Élice (en contra, porque aduce que la democracia no debe ser elitista). 188. Y advertimos que lejos estaba de nosotros cualquier tipo de menosprecio, racismo o burla hacia Supa 189. (aunque anticipábamos que su línea de defensa para justificar sus "horrores ortográficos" sería la victimización y acusarnos de racistas, excluyentes, etc.). 190. Aquí para nada importaba si la escritora era rubia 191. o andina, 192. si era Hilaria Supa 193. o Luciana León 194. (y sospechamos que seguramente no habría habido esa reacción de haberse tratado de León. 195. Incluso con ella sí que muchos colegas y caricaturistas suelen ser muy racistas, 196. pintándola siempre como frívola y bruta solo por ser 
rubia y bonita. 197. Y nunca he visto que el Congreso proteste por eso).

198. Pero la cosa fue más patética de lo que pensaba. 199. Salvo Aurelio Pastor y Martha Hildebrandt, 200. el resto habló pura demagogia 201. por cerca de dos horas de valioso tiempo congresal, 202. en una demostración de espíritu de cuerpo 203. "otoronguista" 204. y de búsqueda de cámaras 205. (Sasieta es la non plus ultra en eso, ya cayendo en la huachafería), 206. lo que evidenció un paternalismo proteccionista hacia ella, 207. como si fuera una menor de edad que no pudiera defenderse, 208. actitud que más bien me pareció hasta racistoide.

209. Y particularmente, me decepcionó Guido Lombardi 210. con eso de que se había violado la intimidad de Supa. 211. No entiendo cómo alguien que ha sido periodista puede decir un disparate así. 212. Parece que hubiera trabajado en otra cosa. 213. Ellos son personajes públicos 214. y funcionarios públicos a la vez, 215. además de estar en el lugar más público del país, 216. esa ágora abierta que es el Congreso. 217. Por todo ello es que están siempre bajo la lupa de la ciudadanía y la prensa. 218. ¿ No han visto cómo la prensa inglesa fotografió unos expedientes que descuidadamente cargaba el jefe del servicio de inteligencia? 219. ¿Acaso no se fotografió lo que escribió Fujimori en una sesión del juicio o los papelitos que se pasaban Montesinos y Wolfenson o el Blackberry de Raffo? 220. ¿Eres o no periodista, compadre?

221. Y lo cortés no quita lo valiente: 222 . si he herido la sensibilidad de Supa, 223. pues ofrezco mis disculpas. 224. Pero el artículo está bien hecho; 225 . se han recogido opiniones opuestas, 226. no miente, no difama, no injuria y menos discrimina. 227. Solo recoge una realidad: 228. la señora escribe muy mal en castellano 229. (y ojo que su producción legislativa es ínfima). 230. Y tenemos todo el derecho de cuestionar que gente sin instrucción superior esté en el Congreso. 231. Faltaba más. 